\title{
The Role of Self-Compassion and Ego Strength on Secondary Post-Traumatic Stress Disorder in Wives of War Veterans
}

\author{
Abdolmalki. $\mathrm{L}^{1}$ \\ ${ }^{*}$ Amiri. $\mathrm{H}^{2}$ \\ Hosseini. SS ${ }^{3}$ \\ Amirpour. $\mathrm{B}^{4}$ \\ Afshariniya. $\mathrm{K}^{5}$ \\ 1- Ph.D. Student of Psychology, \\ Psychology Department, \\ Faculty of Humanities, \\ Kermanshah Branch, Islamic \\ Azad University, Kermanshah, \\ Iran. \\ 2- ( ${ }^{\star}$ Corresponding Author) \\ Ph.D. in Psychology, Assistant \\ Professor, Psychology \\ Department, Faculty of \\ Humanities, Kermanshah \\ Branch, Islamic Azad \\ University, Kermanshah, Iran. \\ Email:Ahasan.amiri@yahoo.com \\ 3- Ph.D. in Psychology, Assistant \\ Professor, Department \\ of Psychology, Faculty of \\ Humanities, Kermanshah \\ Branch, Islamic Azad \\ University, Kermanshah, Iran. \\ 4- Ph.D. in Psychology, Assistant \\ Professor, Psychology \\ Department, Faculty of \\ Humanities, Payame-Noor \\ University Tehran, Tehran, \\ Iran. \\ 5- Ph.D. in Consulting, Assistant \\ Professor, Psychology \\ Department, Faculty of \\ Humanities, Kermanshah \\ Branch, Islamic Azad \\ University, Kermanshah, Iran.
}

\begin{abstract}
Introduction: Since the World Health Organization has introduced mental health something beyond the mere absence of mental illness, Researches increasingly focus on positive personality traits and individuals' internal resources in the coping of psychological distress.
\end{abstract}

Objective: The present study was aimed to investigate the role of self-compassion and ego strength on secondary post-traumatic stress disorder in wives of the war veterans.

Materials and Methods: In this descriptive correlational study, our final sample consisted of 152 participants, who were the wives of war veterans with secondary post-traumatic stress disorder in Kermanshah province in 2019. The subjects were selected by purposive sampling method. To collect the data Reis et al.'s Self-Compassion Scale, psychological ego strength scale and Secondary Trauma Questionnaire (STQ) were used. Data were analyzed using the Pearson correlation coefficient and simple linear Regression by SPSS 25.

Results: The results indicated that the mean score for variables was: secondary post-traumatic stress $(63.43 \pm 10.55)$, Self-compassion (20.91 \pm 7.15$)$ and ego strength $(60.07 \pm 10.69)$. Moreover, Both Self-compassion $(\mathrm{r}=-0.416, \mathrm{P}<0.05)$ and ego strength $(\mathrm{r}=-0.278)$ had negative significant correlation with secondary posttraumatic stress disorder. Based on regression analysis, Self-compassion $(\beta=-0.37)$ and ego strength $(\beta=-0.20)$ were the negative significant predictors of secondary post-traumatic stress.

Discussion and Conclusion: Based on the findings of this research, reducing the level of positive personality traits, such as the self-compassion and ego strength as a source of coping in the secondary victims of trauma, the risk of their Psychopathology increases. It is suggested that the role of these factors in treating trauma and stressrelated disorders be considered.

Keywords: Compassion Fatigue, Ego, Post-Traumatic, Stress Disorders, Spouses, Veterans. 


\title{
نقش خودشفتى و نيرومندى ايتَو در اختلال استر ستروماتيك ثانويه همسران جانبازان جنك
}

\author{
ليلا عبدالملكى"، "حسن اميرى"، سعيده سادات حسينى"، برزو اميريور"، كريم افشارى نياه
}

جكيده

مقدمه: از آنجايى كه سازمان بهداشت جهانى، سلامت روان را جيزى فراتر از فقدان محض بيمارى معرفى كرده است،

تمركز يزوهشى بر خصوصيات مثبت شخصيتى و منابع درونى افراد در مقابله گرى با آشفتگى هاى روانى فزونى يافت. هدف: يزوهش حاضر، با هدف بررسى نقش خودشفقتى و نيرومندى ايكو در اختلال استرس تروماتيك ثانويه همسران

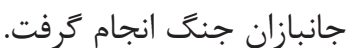

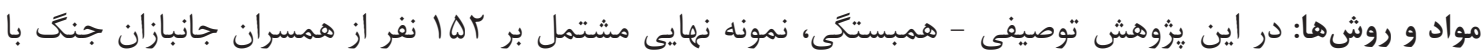

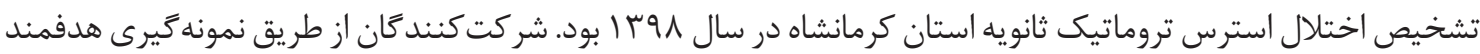

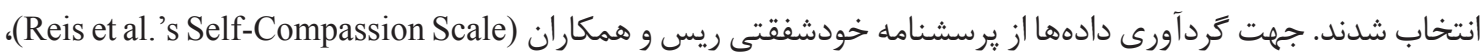
مقياس روانشناختى قدرت ايكو (Psychological Ego Strength Scale) و مقياس آسيب ثانويه Secondary Trauma)

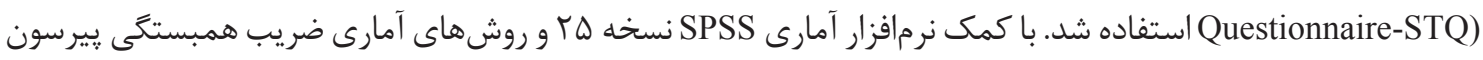
و ركرسيون خطى ساده دادها تحليل شدند.

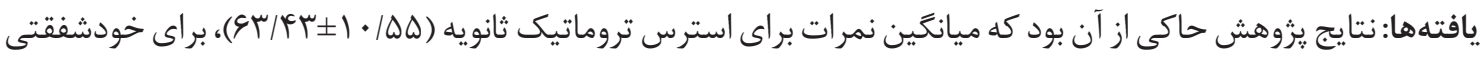

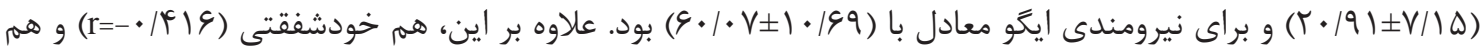

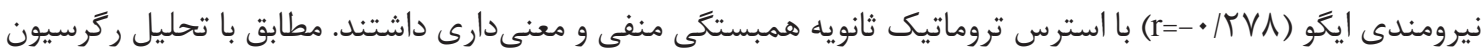

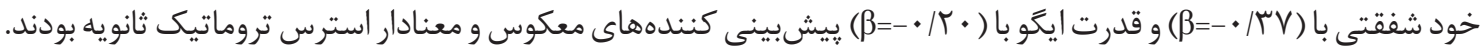
بحث و نتيجه كيرى: بر اساس نتايج اين مطالعه، تقليل صفات مثبت شخصيتى مانند خودشفقتى و قدرت ايكو به عنوان

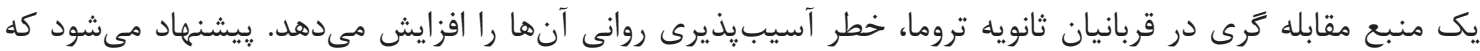
نقش اين عوامل در درمان اختلالات وابسته به تروما و استرس لحاظ شود. كلمات كليدى: اختلال استرس يس از سانحه، خستخى شفقت، ايخو، جانبازان، همسران.

\begin{tabular}{|c|c|c|}
\hline I & 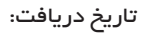 & 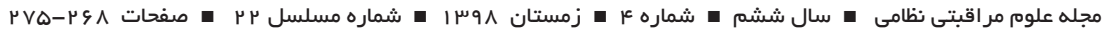 \\
\hline $1 \mu q \Lambda / 9 / \mu q$ & 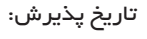 & \\
\hline | & تتشار: & \\
\hline
\end{tabular}

زمان حاضر است كه به صورت غيرارادى و در قالب خاطرات و

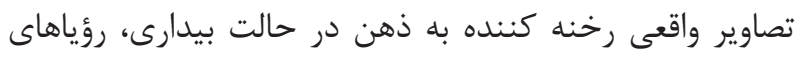
ييشامد تروماتيك در زندگى به عنوان يك رويداد يا مجموعهاى تكرارى و كابوسهاى شبانه تظاهر مىيابند (1، ؟). تجارب از رويدادهاى به شدت تهديد كننده و خوفناك تعريف مى شوند. تروماتيك با طيف گسترداى از ييامدهاى منفى همراه هستند، خصيصه ضرورى اين ييشامد تجربه مكرر واقعه آسيبرسان در 
براى بروز نشانگان اختلال استرس تروماتيك ثانويه دارند.

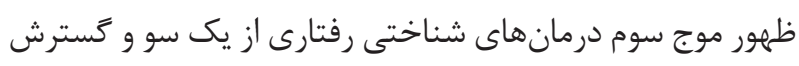

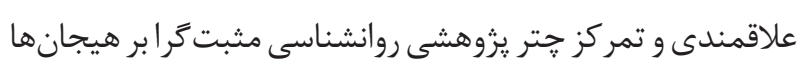

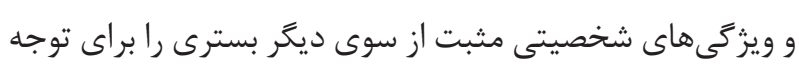

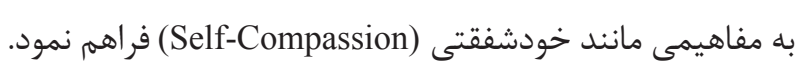

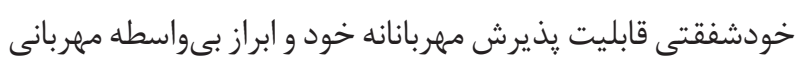

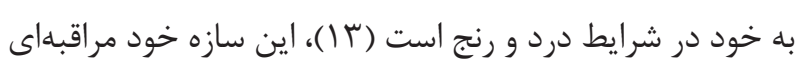
يك موضع منصفانه نسبت به خود است كه در هنحام مصائب و

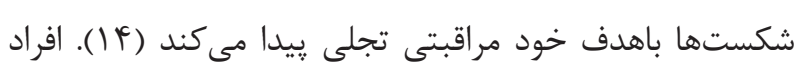

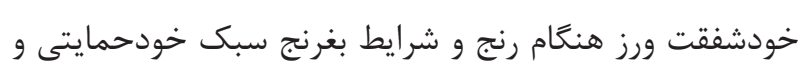

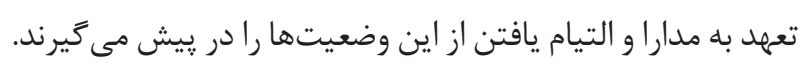
به طور كلى سه مؤلفه دو قطبى مثبت و منفى براى خودشفقتى

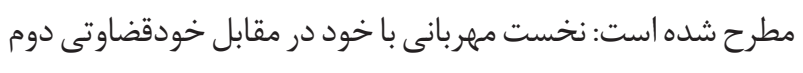

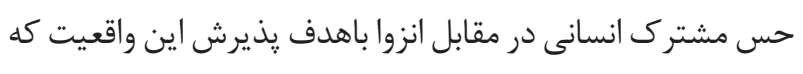

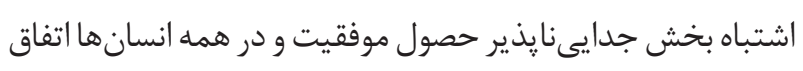
مىافتد و سوم ذهن آكاهى (Mindfulness) در مقابل همانندسازى

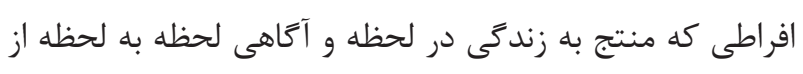

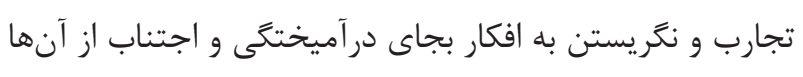

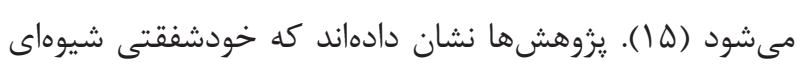

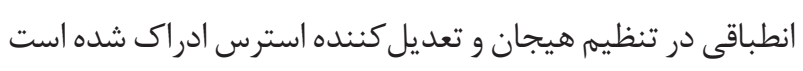
و انعطاف يذيرى روانشناختى از ييامدهاى مطلوب اين خصيصه

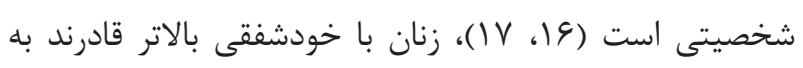
محرك هاى هيجانى ياسخ مناسبترى نشان دهند (1) (IV) و مهممتر اينكه، يزوهشهاى مبتنى بر فراتحليل حاكى از سطوح پايينتر خودشفقتى در زنان نسبت به مردان است (9 (1).

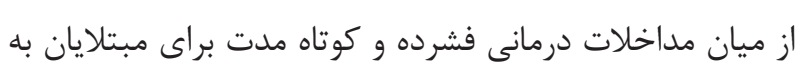

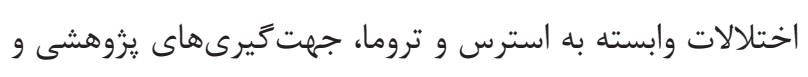
كاربست عملى آنها در رويكرد روان يويشى به نحوى جشمخير

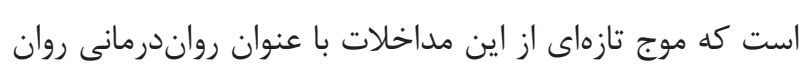

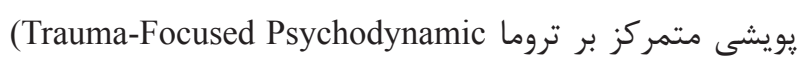

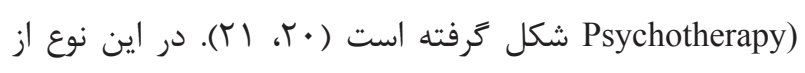
رواندرمانى ها سنجش و بازسازى ساختار مهمم شخصيت يعنى ايخو

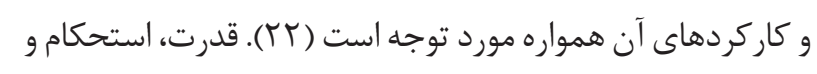

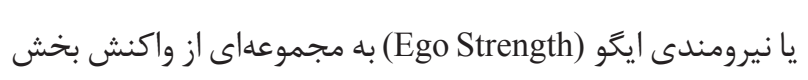

اختلال استرس پس از سانحه شايع تر ين ييامد روانشناختى مواجهه با تروما است (باس). در يازدهمين نسخه از طبقدبندى بينالمللى بيمارىها (International Classification of Diseases, ICD-11) سازمان بهداشت جهانى منتشر شدهاست شش معيار مشخص كننده: يس نكرى هاى تجزيه (Dissociative Flashbacks)؛ كابوس هاى

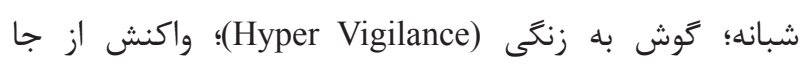
در رفتنهاى طغيانى (Exaggerated Startle Response)؛ اجتناب

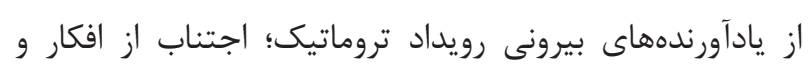

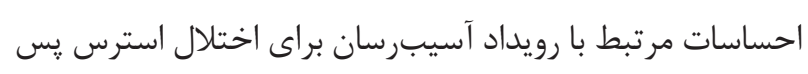

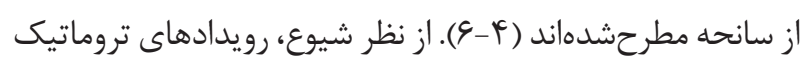

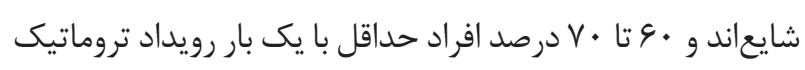

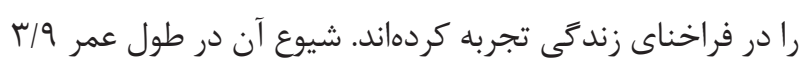

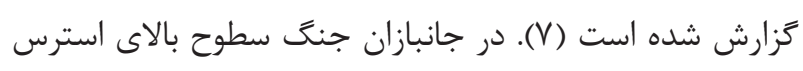

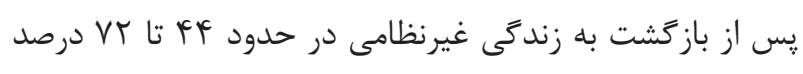

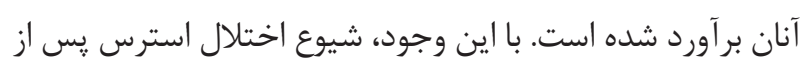

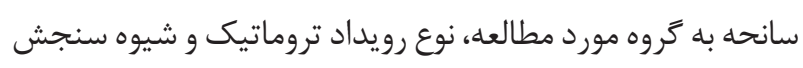
مورد استفاده در تشخيص اختلال بستخى دارد (^). در برخى مواقع به شيوه غيرمستقيم و به واسطه آكاهى يافتن

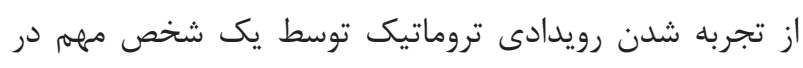
زندىى، هيجانها و رفتارهايى در فرد شكل مى گيرند كه بسيار

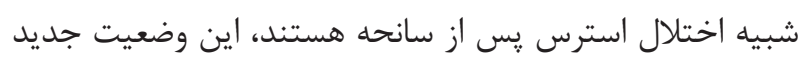
با سببشناسى متفاوت اختلال استرس تروماتيك ثانويه ناميده (Secondary Traumatic Stress) مبتلايان همجنين نشخوار ذهنى (Rumination)، يس نَّرى،

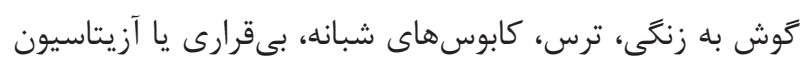

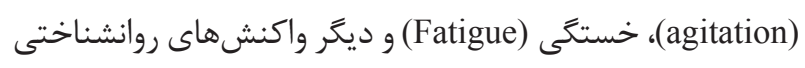
را تجربه مى كنند ( • (). بر اساس نظريه استرس مزمن (Chronic) تعامل نزديك و زندگى طولانى مدت با افراد Stress Theory)

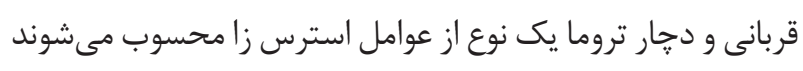
كه در شكلدهى به استرس تروماتيك ثانويه نقش آفرينى مي كند

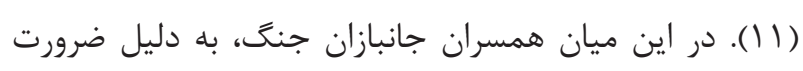

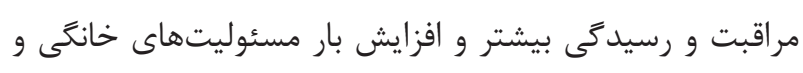

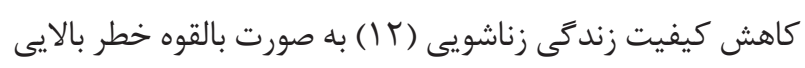


ضمن دريافت كد اخلاق، تمايل به مشاركت آكاهانه در يزوهش. از

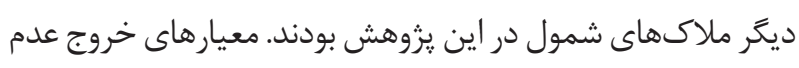

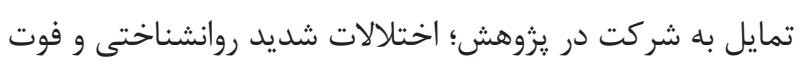

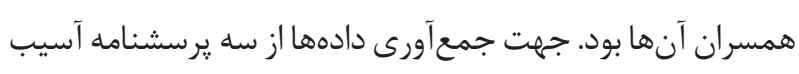

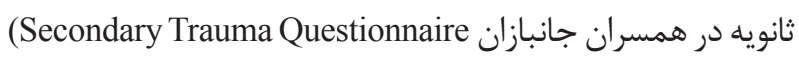
(Reis et al.’s شفقت به خود ريس و همكاران in Warfare -STQ) : و يرسشنامه نيرومندى ايكو ماكستروم و همكاران Markstrom et al.'s Psychological Ego Strength استفاده شد. يرسشنامه آسيب ثانويه در همسران جانبازان Scale)

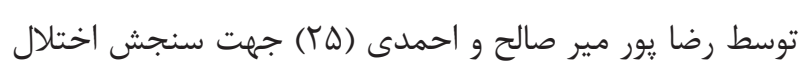

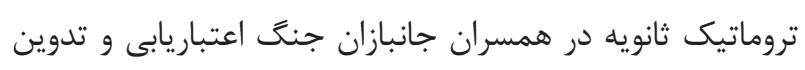

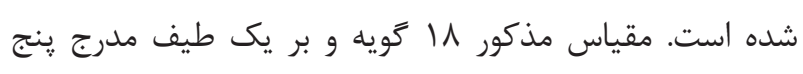

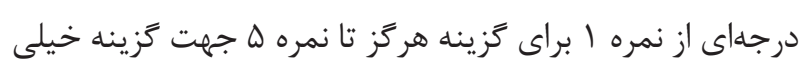

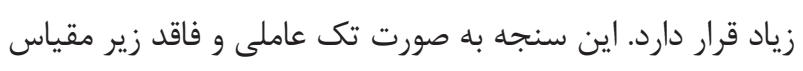

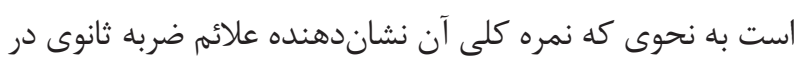

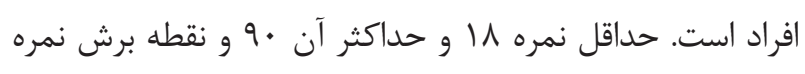
هr جهت تشخيص كذارى اختلال مطرح شده است. سازندًان

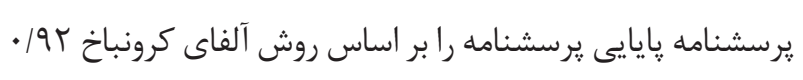

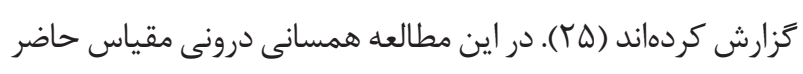

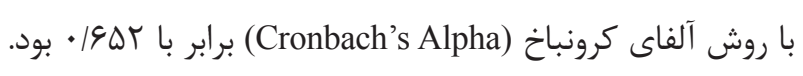

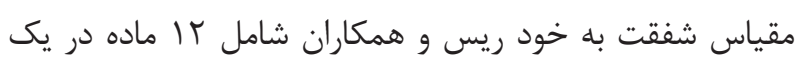
طيف مدرج ه درجهاى از | (تقريباً هركز) تا ه (تقريباً هميشهان

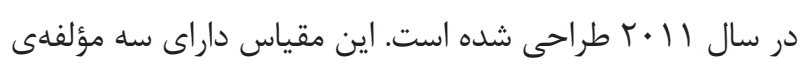

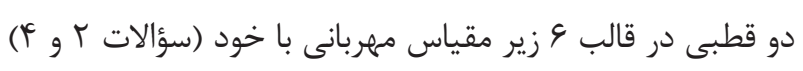

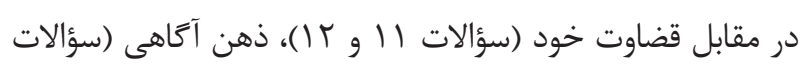

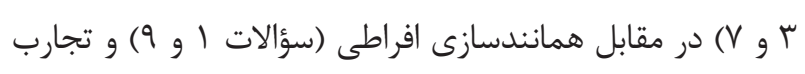

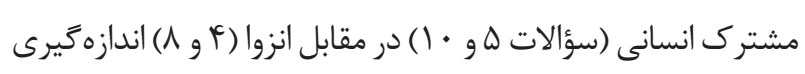
مى كند. اعتباريابى اين مقياس در داخل توسط شهبازى و و همكاران

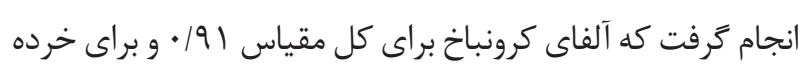

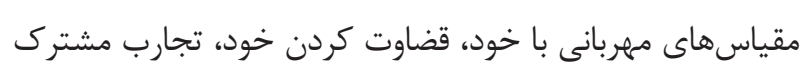

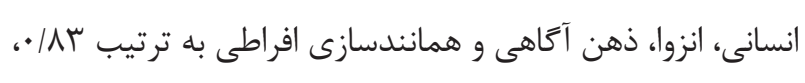

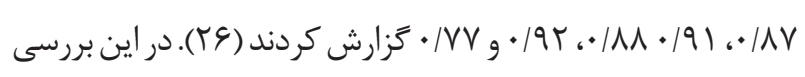

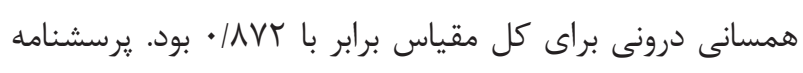

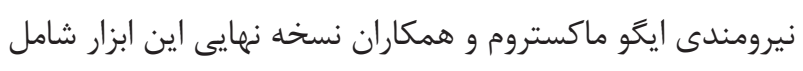

"من " در ساختار شخصيت مانند توانايى كنار آمدن با استرسهاى

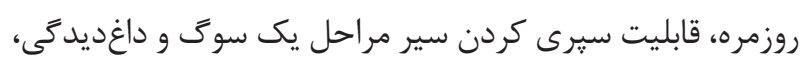
مقابله كرى مناسب با خشم و خصومت، توانايى به تأخير انداختن يك لذت و تحمل ناكامى، توانايى يذيرش يك موقعيت خوشى و

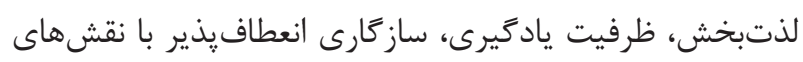

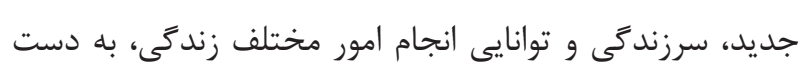

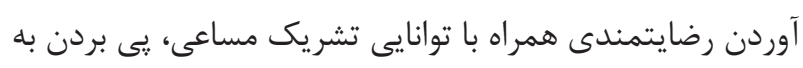

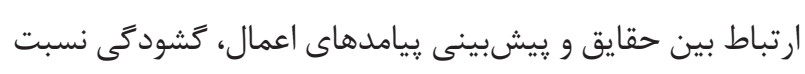

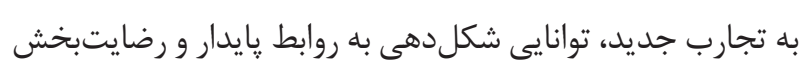

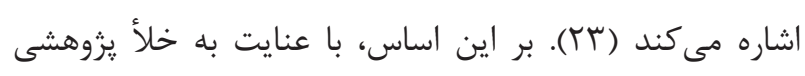

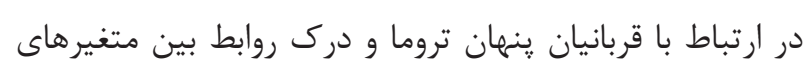
بيشبين يعنى خودشفقتى و نيرومندى ايخو و سهمم تبيين كننده آنها در اختلال استرس تروماتيك ثانويه در همسران جانبازان جنَ، يزوهش حاضر اجرا شد.

\section{مواد و روشها}

يزوهش حاضر از نظر هدف، بنيادى و درعينحال به لحاظ رواظ

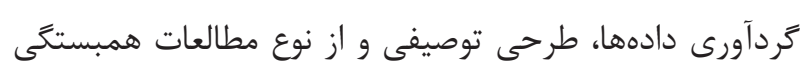
است. اين بررسى به صورت مقطعى و حذشته نكر بر روى همسران

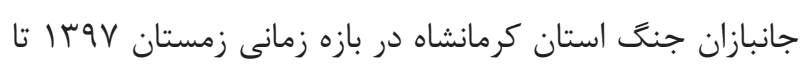

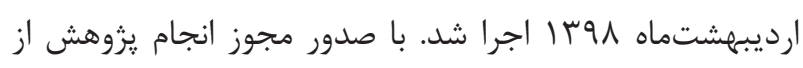
مركز مطالعات و يزوهشهاى بنياد شهيد و امور ايثاركران كشور

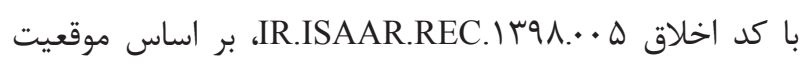
جغرافيايى، نمونههاى آمارى با عنايت به كفايت حجم نمونه در

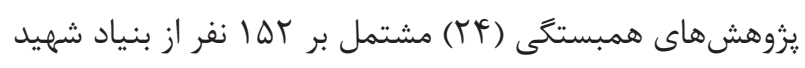
مركز استان و شهرهاى شرقى (هرسين، صحنه و كنكاور ) به شيوه نمونه كيرى هدفمند جهت حصول نتايج دقيقتر انتخاب شدند.

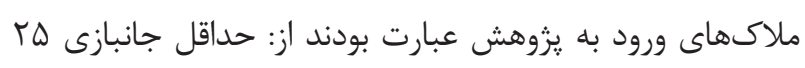

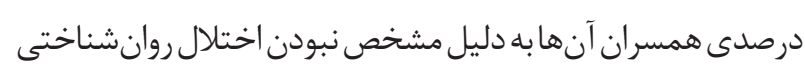
در يروندهها، درج نوع جانبازى اعصاب و روان به تنهايى يا در كنار

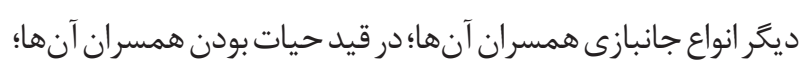

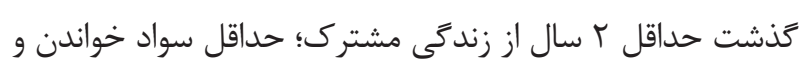

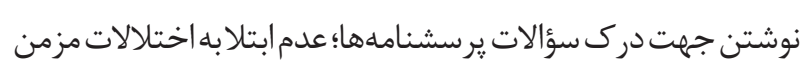

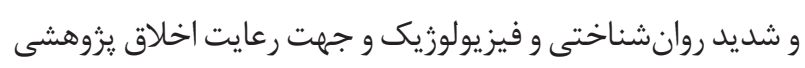




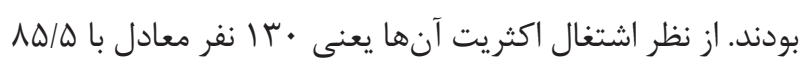

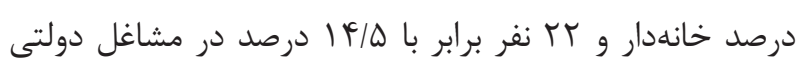
فعاليت داشتند. ميانخين و انحراف استاندارد سن، تعداد فرزندان

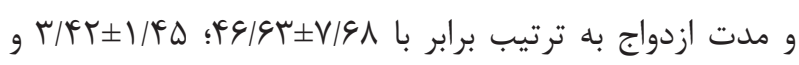
(

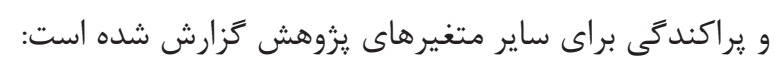

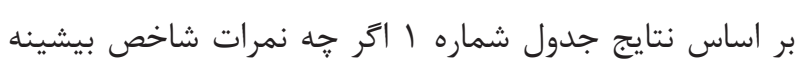

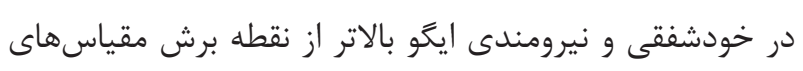

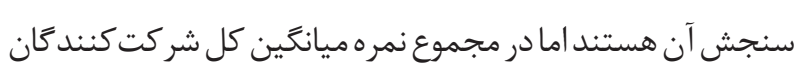

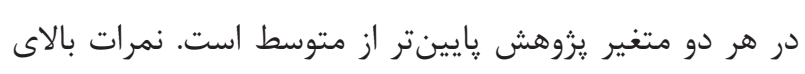

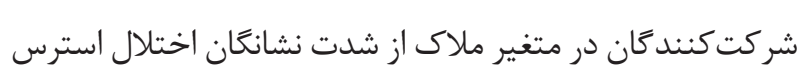

جدول ا- اندازههاى مركزى و براكندَى جهت توصيف متغيرهاى بزوهش

$(N=\mid \Delta T)$

\begin{tabular}{|c|c|c|c|}
\hline حداكثر & حداقل & (انحراف معيار) & متغير \\
\hline 99 & rF & FG/GT $(V / 9 \Lambda)$ & سن \\
\hline $\mathrm{v}$ & $\cdot$ & $r / F T(1 / \mathcal{F} \Delta)$ & تعداد فرزندان \\
\hline$\Delta r$ & $r$ & $r q / \Delta \cdot(9 / \Delta q)$ & مدت ازدواج \\
\hline$\Lambda \Delta$ & rV & $9 \mu / \mathbb{A r}^{\mu}(1 \cdot / \Delta \Delta)$ & استرس تروماتيك ثانويه \\
\hline $4 q$ & ir & $r \cdot / 91(V / / Q)$ & خودشفقى \\
\hline 1 . & $r$ & $r / \Delta \Delta(1 / 4 q)$ & تجارب مشترك انسانى \\
\hline $1 \cdot$ & $r$ & 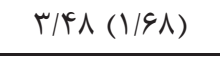 & همانندسازى افراطى \\
\hline 9 & $r$ & $r / T \Delta(1 / G T)$ & انزوا \\
\hline 1. & $r$ & $\mathrm{r} / 0 \cdot(1 / 91)$ & ذهن آكَاهى \\
\hline 9 & $r$ & $r / 4 Q(1 / \Delta \varphi)$ & قضاوت كردن خود \\
\hline$\Lambda$ & $r$ & $r / G F(1 / F F)$ & مهربانى به خود \\
\hline is & 111 & $9 \cdot 1 \cdot V(1 \cdot 199)$ & نيرومندى ايكو مقياسها) \\
\hline r & 11 & $V / \Delta 9(Y / / V)$ & مراقبت \\
\hline k & 11 & $V / \Delta V(T / T \cdot)$ & شايستخى \\
\hline k & IV & $V / V \wedge(Y / Y \wedge)$ & وفادارى \\
\hline f & if & $\Lambda / T V(T / / Q)$ & اميد \\
\hline r & 19 & $V / 11(T / \cdot 9)$ & عشق \\
\hline r & 19 & $V / A T(T / 19)$ & 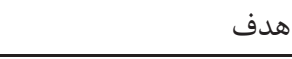 \\
\hline f & IV & $V / \cdot \wedge(1 / 9 F)$ & خواسته \\
\hline r & Ir & $G / \Lambda F(I / \Delta T)$ & خرد \\
\hline
\end{tabular}

جو كويه و در سال 1997 طرحى شده است كه در يك مقياس

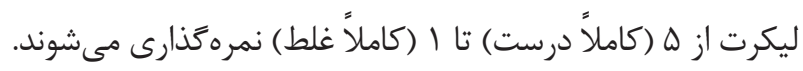

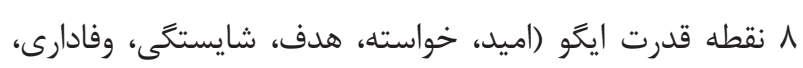
عشق، مراقبت و خرد) را مىسنجد. در اين يزوهش از نسخه كوتاه

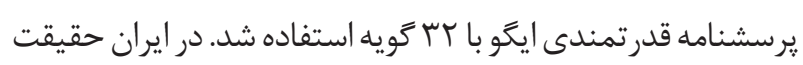

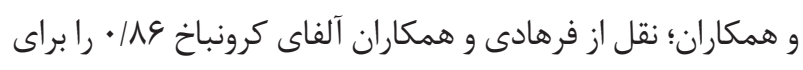
فرم كوتاه كزارش كردند (YV)

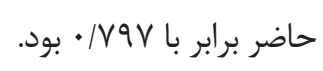

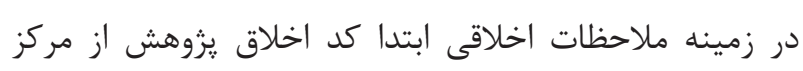

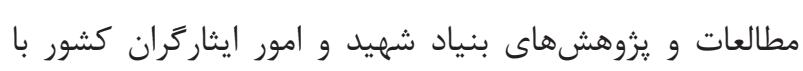

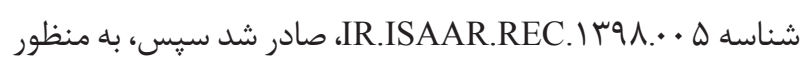
حفظ حريمر رازدارى ضمن تشريح اهداف يزوهش از درج مشخصات

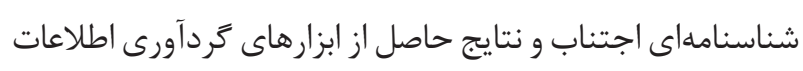
به دنبال درخواست برخى از شركت كنند

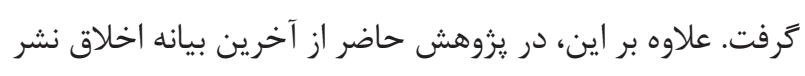

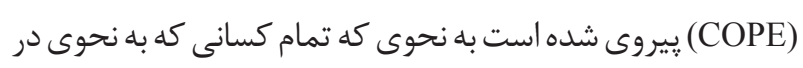
انجام كار دخالت داشتند ولى فاقد معيار نويسندكى (COuthorship) مىباشند در بخش سياسگزارى نام برده شده است؛ عدم ارسال

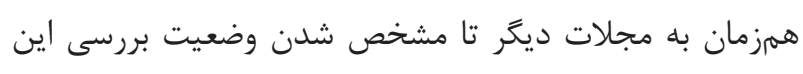

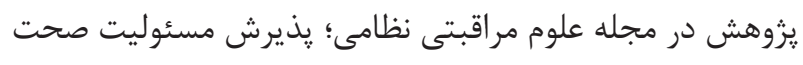

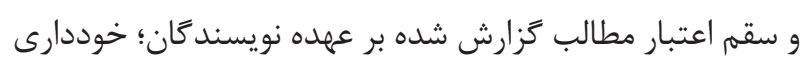

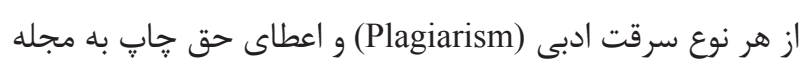
مذكور و توجه به تعارض منافع احتمالى از ديگر موارد تطبيق

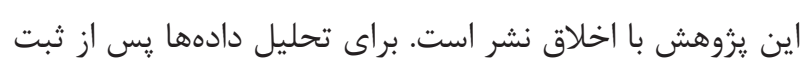

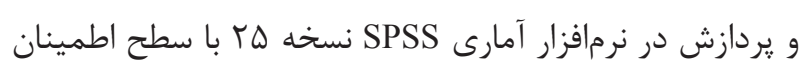

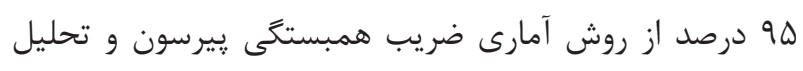
ركرسيون استفاده شده است.

\section{يافتهها}

نتايج مطالعه حاكى از آن بود كه لحاظ سطح تحصيلات اكثريت

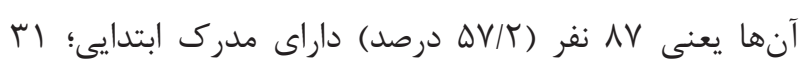

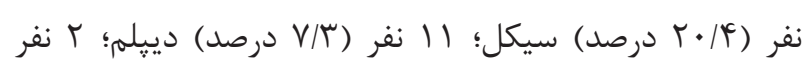

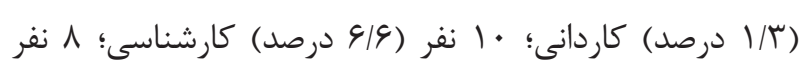

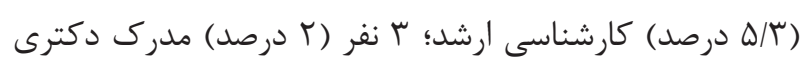




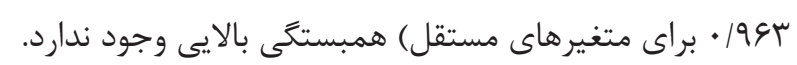

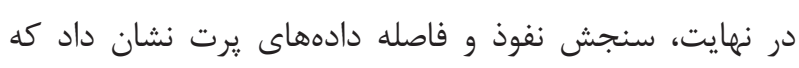

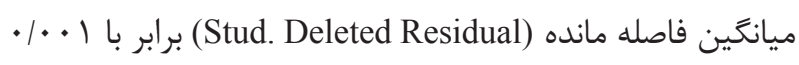

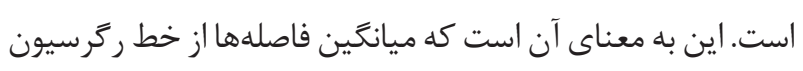

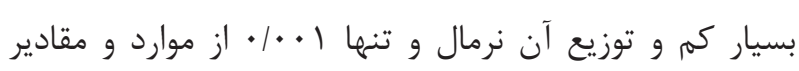

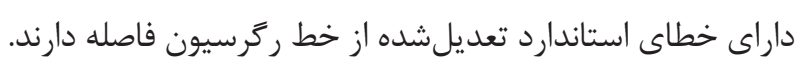

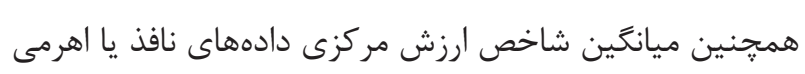
جهت برآورد فاصله مقادير يرت ادهاي ناقذ اهرمي (Centered Leverage Value)

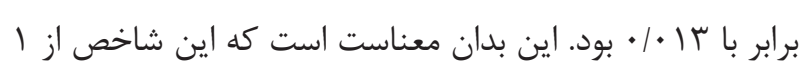

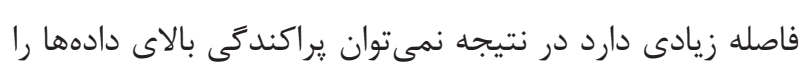

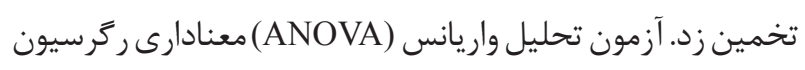

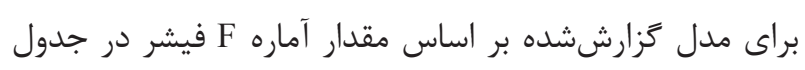

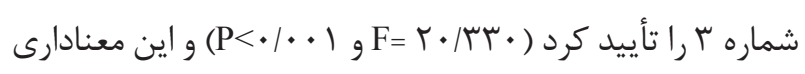
كوياى آن است كه بين متغيرهاى مستقل و وابسته رابطه خطى نَ

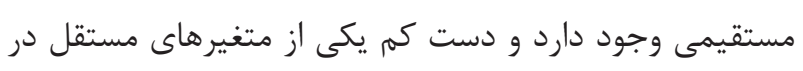
ريشبينى متغير وابسته مؤثر بوده است. در جدول شماره ب نتايج تحليل رَرسيون آمده است:

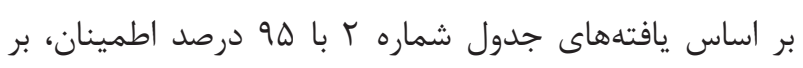
اساس ميزان ضريب تعيين (Rr) در دو متغير خودشفقتى و

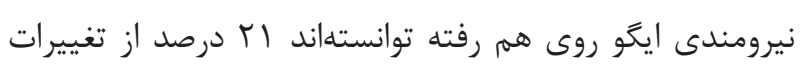

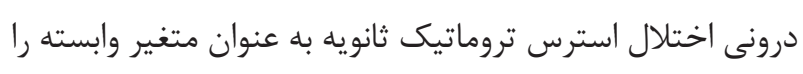

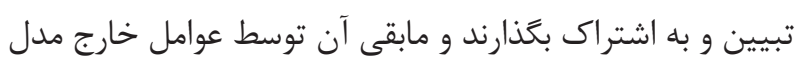
مذكور تبيين مىشود. مقادير به دست آمده براى T با اطمينان

تروماتيك حكايت دارد. به منظور بررسى نقش خودشفقتى و

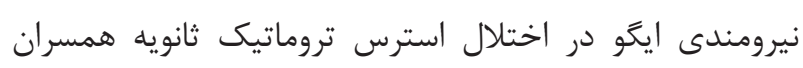

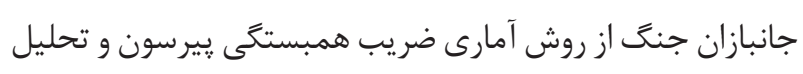

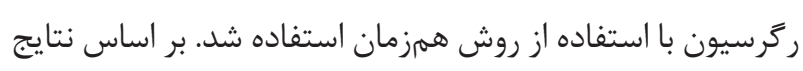

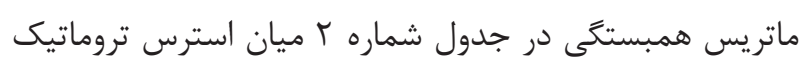

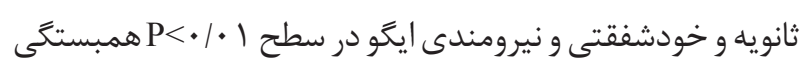

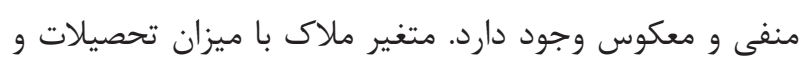
طول مدت ازدواج در سطح | P | P ارتباط معنادارى وجود دارد.

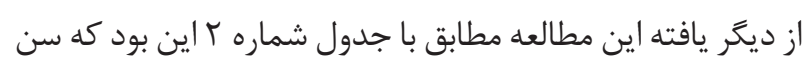
شركت كنند

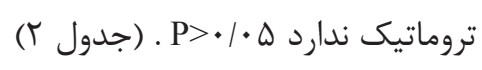

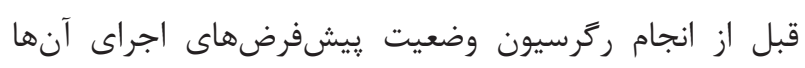
بررسى كه نتايج آن در ادامه ذكرشدهاند. سطح معنادارى آزمون

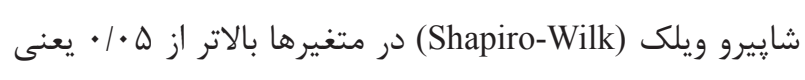
Pارد كه نشاندهنده توزيع بهنجار دادهها است. مقدار

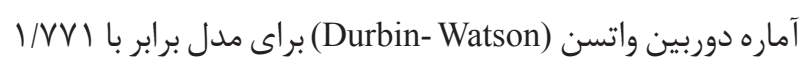

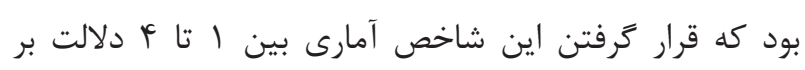

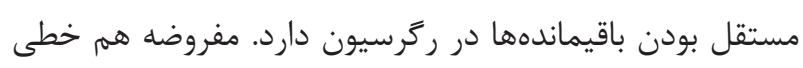

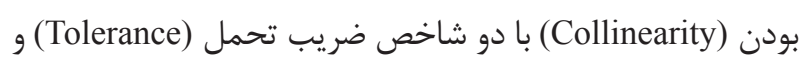

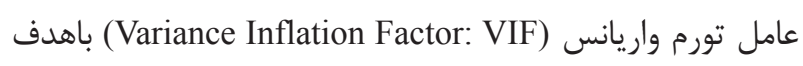
تشخيص مستقل بودن متغيرهاى پيش بين نشان داد كه بين

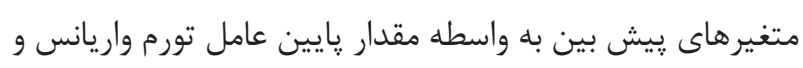

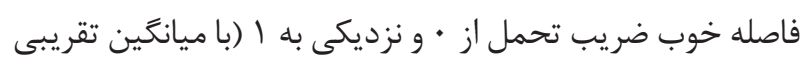

جدول r - ماتريس همبستكى ميان استرس تروماتيك ثانويه با متغير هاى يزوهش

\begin{tabular}{|c|c|c|c|c|c|}
\hline سطح تحصيلات & سن & طول مدت ازدواج & نيرومندى ايگو & خودشفقتى & متغير \\
\hline $\mathrm{r}=-\cdot / \mathrm{r} \cdot \cdot$ & $\mathrm{r}=\cdot 1 \cdot 9 \mathrm{r}$ & r=./Tr & $\mathrm{r}=\cdot / \mathrm{TV \Lambda}$ & $\mathrm{r}=-\cdot\left|\varphi^{c}\right| q$ & \multirow{2}{*}{ استرس تروماتيك ثانويه } \\
\hline $\mathrm{P}<\cdot 1 \cdots 1$ & $\mathrm{P}=\cdot / T F V$ & $\mathrm{P}=\cdot / \cdot \mathrm{r}^{\mathrm{c}}$ & $\mathrm{P}=\cdot / \cdots 1$ & $\mathrm{P}<\cdot \mid \cdots \cdot 1$ & \\
\hline
\end{tabular}

جدول ب- تحليل رَّرسيون به شيوه همزمان جهت پِيشبينى استرس تروماتيك ثانويه بر اساس متغيرهاى پِيش بين

\begin{tabular}{|c|c|c|c|c|}
\hline & ضريب تعيين اصلاحشده Adjusted R'r & 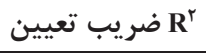 & R همبستخى R & 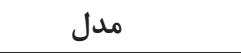 \\
\hline & $\cdot / r \cdot \mu^{c}$ & $\cdot / T / T^{c}$ & . / & 1 \\
\hline سطح معنى دارى P & $\mathrm{T}$ & بتا & شيب خط B & متغيرهاى ي پيش بين \\
\hline $\mathrm{P}<\cdot / \cdots 1$ & $11 / 99$ & & $\Lambda V / T \Lambda$ & a عرض از مبدأ \\
\hline $\mathrm{P}<\cdot / \cdots \cdot 1$ & $-\Delta / \cdot 9$ & $-\cdot / r V$ & $-\cdot 1 \Delta \Delta$ & خود شفقتى \\
\hline$\cdot 1 \cdot \cdot 9$ & $-r / V \wedge$ & $-\cdot / 4 \cdot$ & $-\cdot / / \cdot$ & نيرومندى ايگو \\
\hline
\end{tabular}


منجر مىشود (سب)، بلكه در تنظيم انطباق يافتهتر هيجانها و

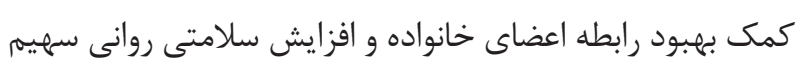

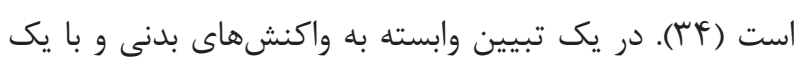

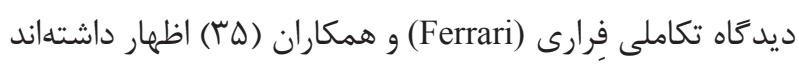

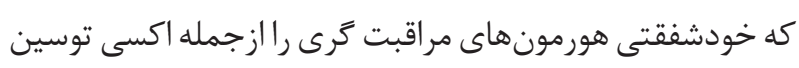
(Oxytocin)

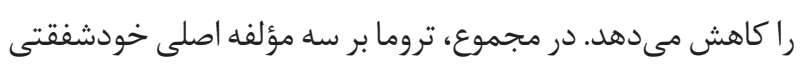

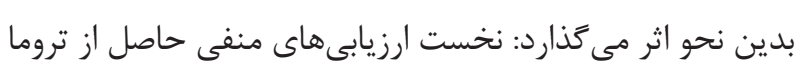

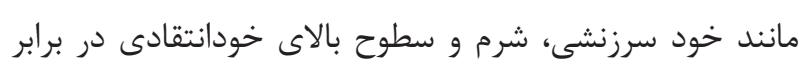

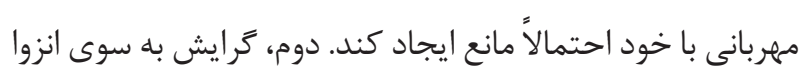

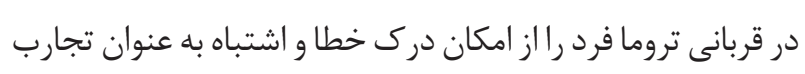
مشترك انسانى بازمى دارد و سوم، نشانگًان بيش انخَيختخى مانند

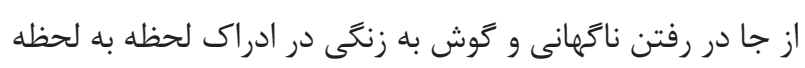

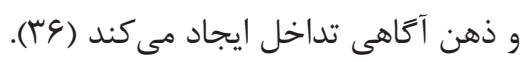

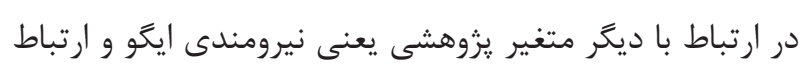

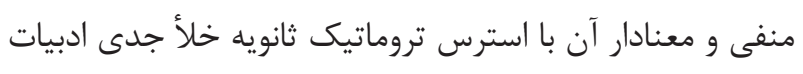

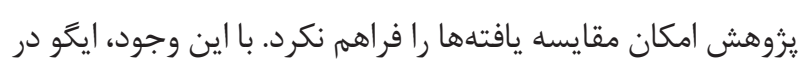

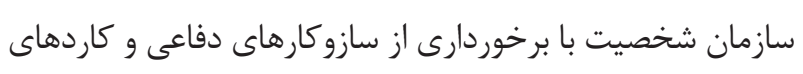

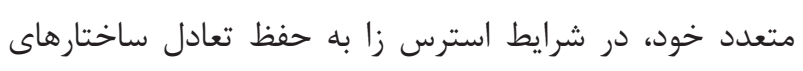

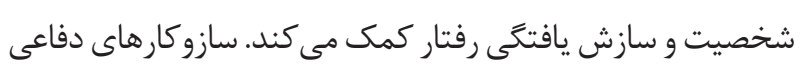
راهبردهاى ناهشيارى هستند كه واكنشهاى افراد را به تعارضات

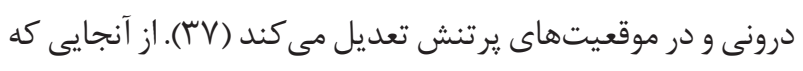

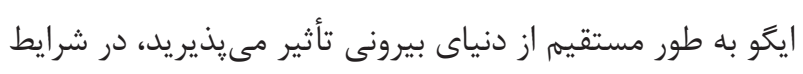

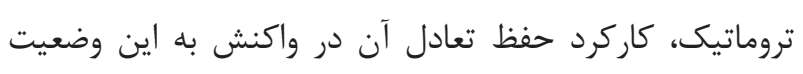
مختل مىشود. در نتيجه تضعيف كنترل تكانهها، مختل شدن

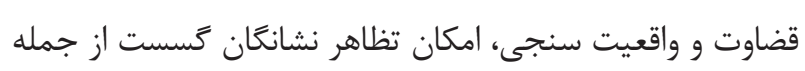

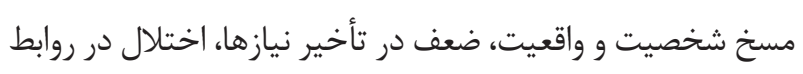
با ديگران و فرايند تفكر من جمله تمركز، توجه و حافظه، احتمال

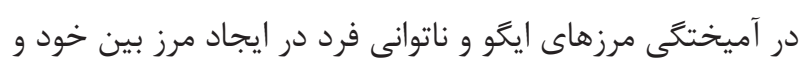

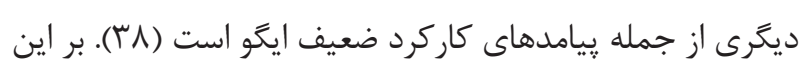

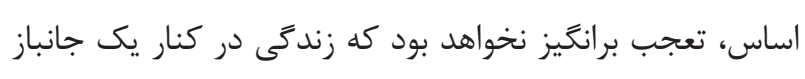

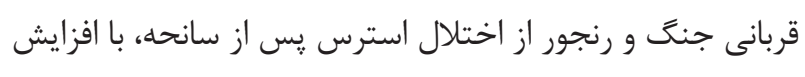
مسئوليت مراقبت كيرى و كاهش كيفيت زندگى زناشويى زمينهساز كاهش استحكام و توانمندى بخش مهام ساختار شخصيت يعنى كئى
ه9 درصد نشاندهنده معنادارى همبستكى ميان متغيرها است

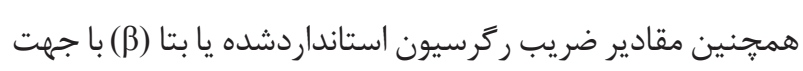
معكوس، شدت اثر متغيرهاى مستقل به ترتيب براى خودشفقتى

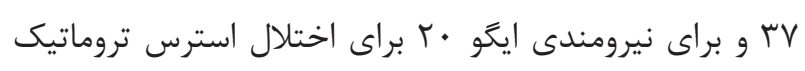
ثانويه را نشان مى دهد.

\section{بحث و نتيجهلَيرى}

يزوهش حاضر باهدف بررسى سهمه پيشبينى كنند

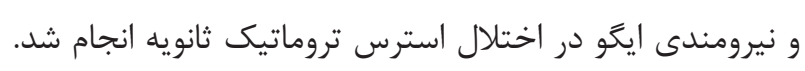

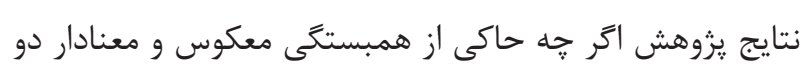

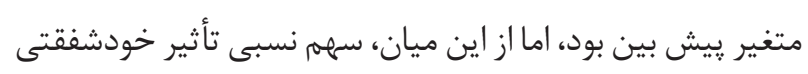

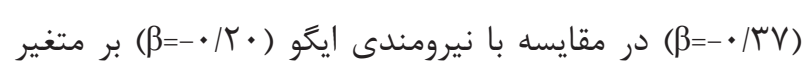

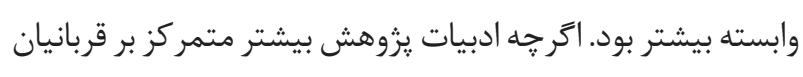

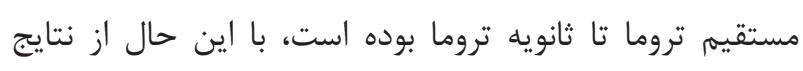

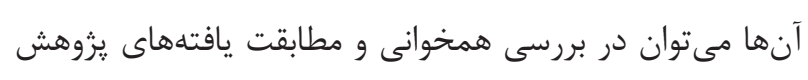
حاضر استفاده كرد. در يزوهش سليكووسكى (Seligowski) و

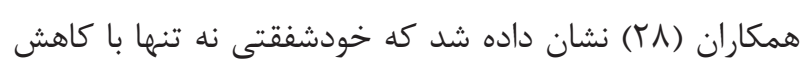

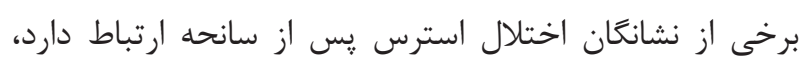

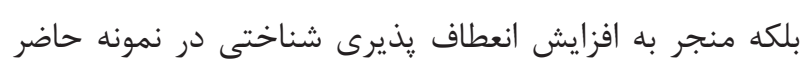

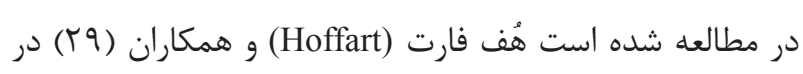
يكى مداخله درمانى مبتنى بر شفقت ورزى با حضور مبتلايان به مدانه اختلال استرس يس از سانحه به اين نتايج دست يافتند كه درمان

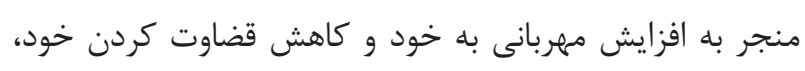

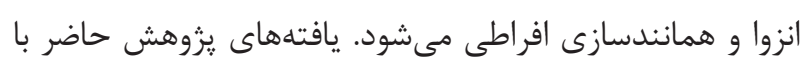

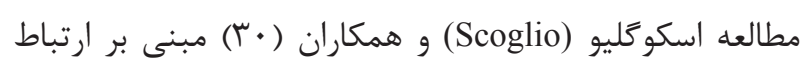

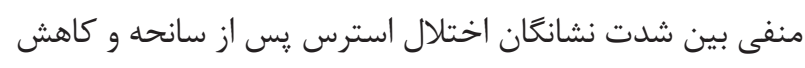
خودشفقتى تا حدودى مطابقت دارد. لانگ (Lang) و همكاران

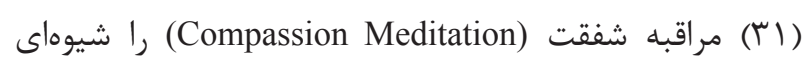
جديد جهت كاهش نشانكان اختلال استرس يس از سانحه براى شركت كنند كان در يزوهش خود معرفى كردند. در تبيين اين نتايج

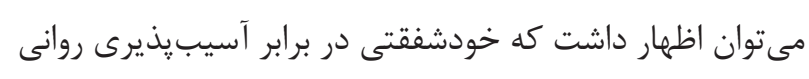

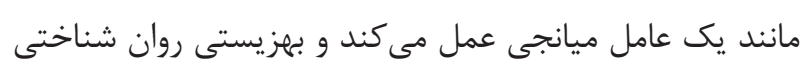

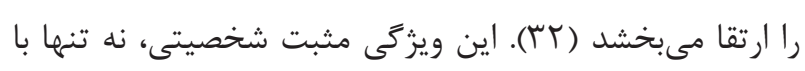

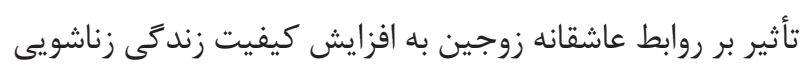




\section{تشكر و قدردانى}

مقاله حاضر بر گرفته از رساله دوره دكترى روانشناسى دانشگاه آزاد اسلامى واحد كرمانشاه است. نويسند حضور شركت كنند در بنياد شهيد سه شهر تشكيل دهنده نمونه آمارى مراتب قدردانى خود را اعلام نمايد. با عنايت به حوزه و زمينه اين مطالعه، رساله حاضر در كميته امور يزوهشى بنياد شهيد و امور ايثاركران كشور

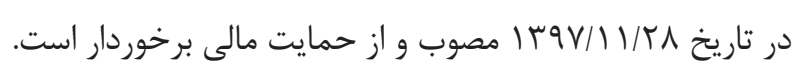

تضاد منافع

بدين وسيله نويسند منافعى در خصوص يزوهش حاضر وجود ندارد.

\section{References}

1- Frewen P, Zhu J, Lanius R. Lifetime traumatic stressors and adverse childhood experiences uniquely predict concurrent PTSD, complex PTSD, and dissociative subtype of PTSD symptoms whereas recent adult non-traumatic stressors do not: results from an online survey study. Eur J Psychotraumatol. 2019;10(1):1606625. DOI: 10.1080/20008198.2019.1606625 PMID: 31105905

2- Brewin CR, Cloitre M, Hyland P, Shevlin M, Maercker A, Bryant RA, et al. A review of current evidence regarding the ICD-11 proposals for diagnosing PTSD and complex PTSD. Clin Psychol Rev. 2017;58:1-15. DOI: 10.1016/j.cpr.2017.09.001 PMID: 29029837

3- Tomich PL, Tolich A. Life is a balancing act: Deviation from a balanced time perspective mediates the relationship between lifetime trauma exposure and optimism. Current Psychology. 2019. DOI: 10.1007/s12144-019-00191-3

4- Barbano AC, van der Mei WF, Bryant RA, Delahanty DL, deRoon-Cassini TA, Matsuoka YJ, et al. Clinical implications of the proposed ICD-11 PTSD diagnostic criteria. Psychol Med. 2019;49(3):483-90. DOI: 10.1017/S0033291718001101 PMID: 29754591

5- Shevlin M, Hyland P, Roberts NP, Bisson JI, Brewin CR, Cloitre M. A psychometric assessment of Disturbances in Self-Organization symptom indicators for ICD-11 Complex PTSD using the International Trauma Questionnaire. Eur J Psychotraumatol. 2018;9(1):1419749. DOI: $\quad 10.1080 / 20008198.2017 .1419749$ PMID: 29372014

6- Somma A, Maffei C, Borroni S, Gialdi G, Fossati A. Post Traumatic Reactions as Individual Differences: Latent Structure Analysis of the International Trauma Questionnaire in Italian Trauma-
ايخو شود (T) (1). از محدوديتهاى مطالعه حاضر، عدم استفاده از مصاحبه بالينى جهت تشخيص دقيقتر اختلال استرس تروماتيك ثانويه، محدود شدن مطالعه به همسران جانبازان جنگ كه عدم امكان تعميمم يافتهها به ساير قربانيان تروماى ثانويه را به همراه خواهد داشت و در نهايت به سبب ماهيت يثرهش همبستخى از استنباط على - معلولى نتايج اين مطالعه اجتناب به عمل آيد. در ييوند با كاربست يافتههاى اين يزوهش، به درمانكران حوزه

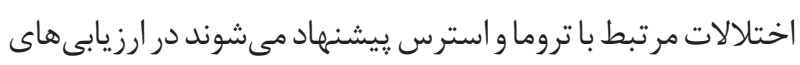
روانشناختى ضمن سنجش ميزان خودشفقتى و نيرومندى ايگو به عنوان منابع درونى فرد، راهبردهاى تقويت آنها را طرحهاى درمانى خود لحاظ كنند. برخلاف محدوديت اين مطالعه، به يزوهشگران آتى ييشنهاد مىشود كه جهت تشخيص دقيقتر علاوه بر :رسشنامه از مصاحبههاى بالينى استفاده شود.

Exposed and Non-Trauma Exposed Adults. Mediterranean Journal of Clinical Psychology. 2019;7(1). DOI: 10.6092/22821619/2019.7.2058

7- Gomez de La Cuesta G, Schweizer S, Diehle J, Young J, Meiser-Stedman R. The relationship between maladaptive appraisals and posttraumatic stress disorder: a metaanalysis. Eur J Psychotraumatol. 2019;10(1):1620084. DOI: 10.1080/20008198.2019.1620084 PMID: 31231479

8- Miao XR, Chen QB, Wei K, Tao KM, Lu ZJ. Posttraumatic stress disorder: from diagnosis to prevention. Mil Med Res. 2018;5(1):32. DOI: 10.1186/s40779-018-0179-0 PMID: 30261912

9- Polak S, Bailey R, Bailey E. Secondary Traumatic Stress in the Courtroom: Suggestions for Preventing Vicarious Trauma Resulting from Child Sexual Abuse Imagery. Juvenile and Family Court Journal. 2019;70(2):69-75. DOI: 10.1111/jfcj.12137

10- Benuto LT, Singer J, Gonzalez F, Newlands R, Hooft S. Supporting Those Who Provide Support: Work-Related Resources and Secondary Traumatic Stress Among Victim Advocates. Saf Health Work. 2019;10(3):336-40. DOI: 10.1016/j.shaw.2019.04.001 PMID: 31497330

11- Owens-KingAP.Secondarytraumaticstressandself-careinextricably linked. Journal of Human Behavior in the Social Environment. 2019;29(1):37-47. DOI: 10.1080/10911359.2018.1472703

12- LahavY,Renshaw KD, SolomonZ. DomesticAbuse andForgiveness among Military Spouses. J Aggression, Maltreatment \& Trauma. 2018;28(2):243-60. DOI: 10.1080/10926771.2018.1531335

13- Wollast R, Riemer AR, Bernard P, Leys C, Kotsou I, Klein O. How self-compassion moderates the effect of body surveillance on subjective happiness and depression among women. Scand J 
Psychol. 2019;60(5):464-72. DOI: 10.1111/sjop.12553 PMID: 31148181

14- Voci A, Veneziani CA, Fuochi G. Relating Mindfulness, Heartfulness, and Psychological Well-Being: the Role of SelfCompassion and Gratitude. Mindfulness. 2018;10(2):339-51. DOI: $10.1007 / \mathrm{s} 12671-018-0978-0$

15- Wong CCY, Knee CR, Neighbors C, Zvolensky MJ. Hacking Stigma by Loving Yourself: a Mediated-Moderation Model of Self-Compassion and Stigma. Mindfulness. 2018;10(3):415-33. DOI: $10.1007 / \mathrm{s} 12671-018-0984-2$

16- Lathren C, Bluth K, Park J. Adolescent self-compassion moderates the relationship between perceived stress and internalizing symptoms. Personality and Individual Differences. 2019;143:3641. DOI: 10.1016/j.paid.2019.02.008

17- Boykin DM, Himmerich SJ, Pinciotti CM, Miller LM, Miron LR, Orcutt HK. Barriers to self-compassion for female survivors of childhood maltreatment: The roles of fear of self-compassion and psychological inflexibility. Child Abuse Negl. 2018;76:216-24. DOI: 10.1016/j.chiabu.2017.11.003 PMID: 29144981

18- Pires FBC, Lacerda SS, Balardin JB, Portes B, Tobo PR, Barrichello CRC, et al. Self-compassion is associated with less stress and depression and greater attention and brain response to affective stimuli in women managers. BMC Womens Health. 2018;18(1):195. DOI: 10.1186/s12905-018-0685-y PMID: 30482193

19- Yarnell LM, Neff KD, Davidson OA, Mullarkey M. Gender Differences in Self-Compassion: Examining the Role of Gender Role Orientation. Mindfulness. 2018;10(6):1136-52. DOI: 10.1007/s12671-018-1066-1

20- Busch FN, Milrod BL. Trauma-Focused Psychodynamic Psychotherapy. Psychiatr Clin North Am. 2018;41(2):277-87. DOI: 10.1016/j.psc.2018.01.005 PMID: 29739526

21- Busch FN, Nehrig N, Milrod B. Trauma-Focused Psychodynamic Psychotherapy of a Patient With PTSD in a Veterans Affairs Setting. Am J Psychother. 2019;72(1):24-8. DOI: 10.1176/appi. psychotherapy.20180019 PMID: 30786735

22- Hayashi H, Takei Y, Fujimori A, Takeuchi I, Hono T. Differences in Ego Functions between Those with Tendency to Atypical Depression and Those with Tendency to Melancholic Depression. Psychology. 2017;08(11):1657-68. DOI: 10.4236/ psych.2017.811109

23- Cyranka K, Rutkowski K, Mielimaka M, Sobanski JA, Klasa K, Muldner-Nieckowski L, et al. Changes in ego strength in patients with neurotic and personality disorders treated with a short-term comprehensive psychodynamic psychotherapy. Psychiatr Pol. 2018;52(1):115-27. DOI: 10.12740/PP/OnlineFirst/40020 PMID: 29704419

24- Delaware A. Research methods in psychology and educational sciences. Tehran: Virayesh; 2016.

25- Rezapour Mirsaleh Y, Ahmadi K. Psychometric Characteristics of Secondary Trauma Questionnaire (STQ) in Warfare. Iranian J Psychiatry and Clinical Psychology. 2017;23(3):348-61. DOI: 10.29252/nirp.ijpcp.23.3.348

26- Shahbazi MR, Moghami E, Jelodari A. Confirmatory factor analysis of the Persian version of the Self-compassion rating scalerevised. J Psychol Models Methods. 2015;6(19):31-96.

27- Farhadi M, Yarmohamadi Vasel M, Zoghi Paidar M, Chegini A. The Efficacy of Hypnotherapy Based on Ego Strengthening on Treatment of Major Depression in Female-Headed Households. Journal of Psychological Achievements. 2017;24(1):63-78.

28- Seligowski AV, Miron LR, Orcutt HK. Relations Among SelfCompassion, PTSD Symptoms, and Psychological Health in a Trauma-Exposed Sample. Mindfulness. 2014;6(5):1033-41. DOI: 10.1007/s12671-014-0351-x

29- Hoffart A, Oktedalen T, Langkaas TF. Self-compassion influences PTSD symptoms in the process of change in trauma-focused cognitive-behavioral therapies: a study of within-person processes. Front Psychol. 2015;6:1273. DOI: 10.3389/fpsyg.2015.01273 PMID: 26379596

30- Scoglio AAJ, Rudat DA, Garvert D, Jarmolowski M, Jackson C, Herman JL. Self-Compassion and Responses to Trauma: The Role of Emotion Regulation. J Interpers Violence. 2018;33(13):201636. DOI: 10.1177/0886260515622296 PMID: 26681787

31- Lang AJ, Malaktaris AL, Casmar P, Baca SA, Golshan S, Harrison T, et al. Compassion Meditation for Posttraumatic Stress Disorder in Veterans: A Randomized Proof of Concept Study. J Trauma Stress. 2019;32(2):299-309. DOI: 10.1002/jts.22397 PMID: 30929283

32- Bluth K, Neff KD. New frontiers in understanding the benefits of self-compassion. Self and Identity. 2018;17(6):605-8. DOI: 10.1080/15298868.2018.1508494

33- Jacobson EHK, Wilson KG, Solomon Kurz A, Kellum KK. Examining self-compassion in romantic relationships. J Contextual Behav Scie. 2018;8:69-73. DOI: 10.1016/j.jcbs.2018.04.003

34- Murfield J, Moyle W, Jones C, O’Donovan A. Self-Compassion, Health Outcomes, and Family Carers of Older Adults: An Integrative Review. Clin Gerontol. 2019:1-14. DOI: 10.1080/07317115.2018.1560383 PMID: 30612532

35- Ferrari M, Hunt C, Harrysunker A, Abbott MJ, Beath AP, Einstein DA. Self-Compassion Interventions and Psychosocial Outcomes: a Meta-Analysis of RCTs. Mindfulness. 2019;10(8):1455-73. DOI: 10.1007/s12671-019-01134-6

36- Inwood E, Ferrari M. Mechanisms of Change in the Relationship between Self-Compassion, Emotion Regulation, and Mental Health: A Systematic Review. Appl Psychol Health Well Being. 2018;10(2):215-35. DOI: 10.1111/aphw.12127 PMID: 29673093

37- Di Giuseppe M, Ciacchini R, Piarulli A, Nepa G, Conversano C. Mindfulness dispositions and defense style as positive responses to psychological distress in oncology professionals. Eur J Oncol Nurs. 2019;40:104-10. DOI: 10.1016/j.ejon.2019.04.003 PMID: 31229199

38- Durmaz YC, Unsal G. Study of validity, reliability in accordance with Turkey conditions in ego functions assessment scale. Perspect Psychiatr Care. 2019;55(3):509-16. DOI: 10.1111/ppc.12357 PMID: 30767235 